\title{
The Main Directions of Reallocation of Industrial Enterprises Manufacturing Resources
}

\section{Babenko Inna Viktorovna}

\author{
Southwest State University, 50 let Oktyabrya ul., 94, 305040, Russia; babenkoinny@gmail.com
}

\author{
Doi:10.5901/mjss.2015.v6n6p369
}

\begin{abstract}
In the current context optimizing manufacturing resources is one of the factors increasing the performance of enterprises. Along with the question of optimizing the level of aggregate inventory in the system of material technical supply the problem of allocating it in the commodity distribution network from suppliers to consumers is of great importance. The latter one is closely related to the planning of direct long-term relationships that contribute to the concentration of material flow in the production system, which, on the one hand, leads to decreasing the levels of over-norm and inoperative resources, and, on the other hand, leads to reducing the deficit of inventory. To optimize the allocation of inventory in the commodity distribution network our paper suggests some directions of redistributing the manufacturing inventory of industrial enterprises. The meso-level system of redistributing manufacturing inventories makes it possible to manipulate them in connection with the appearance of overnorm inventories or resources shortage. At the level of enterprises (group of companies) the system of inventory redistribution is designed to control material flow from suppliers of material resources to the end consumer.
\end{abstract}

\section{Introduction}

The relevance of studying the models of inventory management is caused, firstly, by the complexity and diversity of management process, and, secondly, by a large proportion of logistical costs in overall enterprise costs. The primary value of inventory management models is to increase the qualitative level of meeting various kinds of needs by material resources and improving the reliability of economic system performance. The main reserves of increase of efficiency of use the reserves of materials are concluded in the improvement of production management, including such functions of management as rationing of stocks, the organization and planning of the movement of materials from deliveries of raw materials from shipment of finished goods to consumers. Importance of questions of effective management of material streams at the industrial enterprise defined by that size and dynamics of a turn of material and monetary resources has essential impact on economic results of economic activity. Problem of improvement of management of material stocks and streams was paid and paid much attention of scientists-economists and specialists of the enterprises. The problems connected with questions of stockpile management both at the level of the enterprise and on meso - level, were developed by many native and foreign scientists and practicians.

In the first third of the 20th eyelid, a number of articles devoted to questions of stockpile management by authors such as the F. Harris (1915) Stefanik-Almeyera (1927), K. Andlera (1929) and R. Wilson (1934).

The questions of the theory of inventory management were considered by the following authors: Anikin B. A., Belyaev Yu.A., Goldobina H.H., Golenko D. I., Inyutina K.V. Thus, authors developed the methods and models of inventory management intended for resources of organization. Much attention of scientists-economists and specialists of the enterprises dedicate to problems of improvement of management of material stocks and streams. However, at all undoubted importance of this problem its theoretical study isn't complete. Practical techniques operate with the integrated cost indexes that is too difficult for management organizations.

So, the development of models of rationing and operational management of inventory on the basis of complex model of dynamics of material and cash in a commercial cycle of the enterprises is topical.

The manufacturing process is provided by material resources and material technical supply system, which carries out the allocation function being as an intermediary between suppliers and consumers. Along with the question of optimizing the level of aggregate inventory in the system of material technical supply the problem of allocating it in the commodity distribution network from suppliers to consumers is of great importance. Improving the allocation of aggregate inventory occurs while improving production and warehouse structures. The latter one is closely connected with the planning of direct long-term relationships, which directly affects the allocation of production means inventory. The right choice of economic relations is not only an important factor of improving the structure of aggregate inventory, but it also significantly influences the entire production process and production efficiency. With direct long-term economic 
relationships, the number of suppliers is reduced for certain types of products, which contributes to the concentration of material flow in the production system. Long-term economic relations are planned on the basis of prospective development goal decision and production location including production-transportation problem goals of advanced planning of the factors which promote to keeping relations.

\section{Materials and Methods}

The systems of inventory management must be created at different levels of the national economy and they must include manufacturing and distribution resources. The main goal of such systems at the macro level is planning the volume and structure of aggregate inventory and creating such an economic mechanism that will ensure the achievement of the main objectives of the system.

The meso-level system of inventory management carries out the manipulation of material resources in connection with the occurrence of over norm inventory or lack of resources. At the level of enterprises, inventory management system is designed to control material flow from suppliers of material resources to the end consumer.

At the stage of forming a prospective planning model of inventory structure, gross inventory and the plans of material resources shipments in possible directions serve as the unknown quantities relating to optimization problem. Optimal supply of necessary resources is achieved through the use of progressive forms of supply, and also owing to sufficient amounts of inventory from suppliers, supply and sales agencies. In this regard, it is necessary that suppliers, consumers, supply and sales agencies keep to the rational allocation of material resources stock by choosing optimal levels of inventories. Reducing the level of over norm and unused stock is significant factor, which increases production efficiency. The main factor in reducing the over norm inventory of material and technical resources of enterprises and their branches is their reallocation, leading to the elimination of artificial lack of material resources and improving the efficiency of their use.

The system of resources reallocation must take into account the interests of inventory management at the level of enterprises, at the level of regions, within the industry and among industries with the aim of obtaining the maximum effect. It can be achieved through progressive forms of integration. Regulating the level of inventory at the level of enterprises is aimed at ensuring the compliance with the established standards of normal performance of enterprises. The essence of such regulation at the meso-economic level is manipulating the over norm and unused inventory being available at the enterprises in order to bridge the emerging deficit.

Supply and marketing structure of industries can be represented as a complex directed graph the nodes of which are enterprises or production systems, and the edges are material flows. Moreover, the edges entering the node characterize the enterprise as a consumer, and emerging from it - as a supplier. The degree of synchronous operation of a suppliers and consumers branched network, as well as the efficiency of resources use by each enterprise determines the efficiency of industry in generally, which causes the need to create flexible systems of reallocation of material and technical resources between enterprises and production systems.

In a broad sense, the reallocation of resources is the process of reorganizing the existing material and information flows management system being based on the integration and coordination of all participants' functions in the supply chain "supply of raw materials - production - marketing - distribution". The basis of resources reallocation system involves using the integration aspect in the material flows management system based on the identification of established technological and economic relations of economic entities through the product chain. The optimization of resources reallocation includes two main areas: modeling the routing of supplies and normalizing inventory for each item in the supply chain.

Therefore, the first phase of resources reallocation is to optimize the supply chain and improve its efficiency. The design algorithm of supply chain structure is presented in Figure 1. 


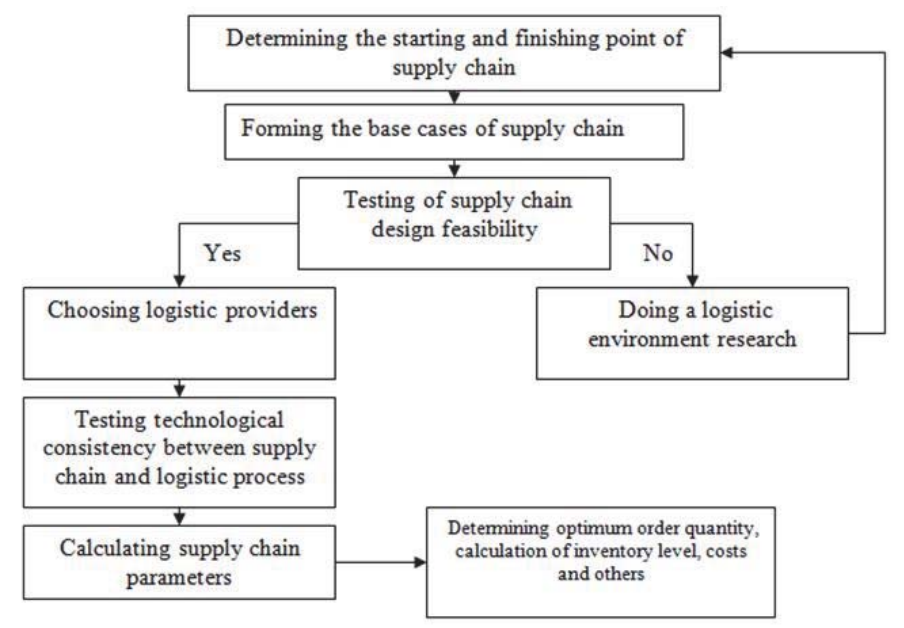

Figure 1 - Design algorithm of supply chain structure

When choosing the optimal variants of logistic systems, it is necessary to consider the balance between profit maximization criteria and logistics costs minimization criteria. Therefore, the objective function should be set as the maximization of profit by each company, including profits, cost of goods manufactured and transaction costs (Formula (1)).

$$
\sum_{m=1}^{M} \sum_{j=1}^{J} \rho_{i m j} q_{i m j}-\sum_{m=1}^{M} f_{i m}\left(q_{m}\right)-\sum_{m=1}^{M} \sum_{j=1}^{J} c_{i m j}\left(q_{i m j}\right) \rightarrow \max
$$

where $\rho_{\text {imj }}$ - the costs per unit produced at the enterprise $i$ by the manufacturer $m$, distributed and saled by the distributor $j$; distributor $j$

$q_{i m j}-$ the quantum of output produced at the enterprise $i$ by the manufacturer $m$, distributed and saled by the distributor $j$

$f_{i m}\left(q_{m}\right)$ - the function of manufacture cost at the enterprise $i$ by the manufacturer $m$, distributed and saled by the

$C_{i m j}\left(q_{i m j}\right)$ - transaction costs at the enterprise $i$ by the manufacturer $m$, distributed and saled by the distributor $j$.

The given formula (1) is based upon the implementation of material flows equality of produced and consumed products. This applies to flows $q_{11}, \ldots$ q $\mathrm{im}, \ldots$ q Im between principal enterprises and their constituent manufacturers, material flows between manufacturers and logistics providers, material flows between logistics providers and consumers.

The second stage is the optimization of management decisions connected with the reallocation of resources, which includes the model of optimal resources redistribution at the meso-level. This model determines the industrial and interindustrial flows of reallocation in order to obtain maximum effect for industries with minimum cost of goods sold.

The essence of the resources redistribution model is to get maximum effect, which results in the increased production output of end products at the regional enterprises with minimal costs associated with the reallocation between enterprises lacking resources and enterprises with surplus stock of resources.

\section{Results and Discussion}

The system of resources reallocation is based upon taking into account the variance of the actual level of resources with the target one. Such variances are caused by numerous factors, which influence production and material technical supply in the process of target figures realization.

For making an optimal resources reallocation decision it is advisable to use the following mathematical model. The limitation reflecting the need to keep balance between satisfied tight resources and the availability of over norm resources, i.e. the condition for surplus inventory limitation: 


$$
\sum_{k \in\{k\}^{i}} x_{i k}=\sum_{j \in\{j\}^{i}} r_{i j},(i \in\{i\}) .
$$

where \{i\}- many types of reallocated resources, i.e. available and for which there is demand;

$\{j\}$ - the number of businesses with surplus inventory of the i type of resource.

$\{k\}$ - the number of businesses having resource shortage of the $i$ type of resource.

The limitation not to exceed the volume of allocated resources in relation to the stated deficit for the enterprise $k$ is presented in (2), taking into account the requirements of nonnegativity of the variables in (3):

$$
\begin{aligned}
& x_{i k} \leq d_{i k} \\
& 0 \leq x_{i k} \leq d_{i k}
\end{aligned}
$$

where $d$-the deficit of $i$ resource for regional enterprises.

The possible criteria for the solution of this problem can be: maximizing the accumulated profit obtained from the output of an enterprise at the expense of involved unused resources in the economic turnover (4), maximizing the release of additional output in value terms (5), maximizing the production of end products in value terms (6), minimizing losses resulting from the failure to meet the plan of supplies by regional enterprises (6):

$$
\sum_{i} \sum_{k} P_{i k} x_{i k} \rightarrow \max
$$

where $P_{i k}$ - the profit from additional output at the enterprise $k$ by means of distributed unit of resource $i$.

$$
\sum_{i} \sum_{k} C_{i k} x_{i k} \rightarrow \max
$$

where $C_{i k}-$ the expression of additional output in monetary terms at the enterprise $k$ by means of distributed unit of resource $i$.

$$
\sum_{i} \sum_{k} P_{i k}^{o} x_{i k} \rightarrow \max
$$

where $\mathrm{C}^{0}{ }_{i k}$ - the expression of end use products output in monetary terms at the enterprise $k$ by means of distributed unit of resource $i$.

$$
\sum_{i} \sum_{k} Q_{i k}\left(d_{i k}-x_{i k}\right) \rightarrow \min
$$

where $Q_{i k}$ - the negative profit as a result of nonfulfillment of supplies plan at the enterprise because of lack of resource $i$.

As an optimization criterion of resources reallocation it is advisable to use a criterion based on the principle of uniform optimization, i.e. to minimize the maximum percentage of deficit dissatisfaction for all enterprises which are deficient in the resource $i$, considering the consequences of deficit dissatisfaction in the resource $i$ for every enterprise. Applying this criterion requires the decomposition of the task according to the types of resources. As a result, the model can be represented as follows:

$$
\begin{aligned}
& \max \beta_{r}^{i}\left(\frac{d_{i k}-x_{i k}}{d_{i k}}\right) \rightarrow \min \\
& \sum x_{i k} \leq \sum r_{i k}, \\
& 0 \leq x_{i k} \leq d_{i k},
\end{aligned}
$$

where $\beta_{r}^{i}$ - the integral heuristic priority of providing the enterprise $k$ with resource $i$,

$r_{i k}-$ the quantity of surplus inventory of the resource i available at regional enterprises.

The estimate $\beta_{r}^{i}$ represents a possible integral effect of satisfying the deficit of an enterprise $k$ with resource $i$. It is determined after ranging branch enterprises according to the degree of production plan fulfillment dependence upon the availability of resource $i$ at an enterprise $k$.

After solving the problem of resources reallocation and using these estimates we are able to form extensional characteristics of optimum satisfaction of resources shortage at regional enterprises.

As a criterion for assessing the effectiveness of resources reallocation it is appropriate to use the criterion of minimizing transport costs associated with resources reallocation. Then, the model of solving the problem of resources reallocation can be represented as follows: 


$$
\begin{aligned}
& \sum_{j} x_{i j k}=x_{i k}, \sum_{j} x_{i j k}=r_{i j} \\
& x_{i j k} \geq 0, \sum_{i} \sum_{k} C_{i j k}^{\mathrm{TP}} X_{\mathrm{jik}} \rightarrow \min \\
& \text { where } \mathrm{X}_{\mathrm{ijk}}^{\mathrm{TP}}-\text { the volume of transportation of resource } i \text { from the enterprise } j \text { to the enterprise } k \text {; } \\
& \mathrm{C}_{\mathrm{ijk}}^{\mathrm{TP}} \text { - the transportation costs of resource } i \text { from the enterprise } j \text { to the enterprise } k .
\end{aligned}
$$

At the third stage, with the purpose of selecting the inventory management models in integrated units it is necessary to formulate the terms of interaction among producers, consumers and intermediaries in logistics systems, i.e. to establish a strategy for inventory management in the supply system under the conditions, where the manufacturer being aimed at maximizing its profits has the ability to set the basic parameters of inventory management system, and at the same time, each consumer carries out an independent economic policy.

\section{Conclusion}

Thus, involving over norm and unused inventory in the production process should be viewed as the construction of a dynamic inventory reallocation system between enterprises with the aim of achieving a stable supply of the production with material resources while having the existing deviations in logistics processes. The functioning of this system is associated with operative handling of the emerging anomalies in the process of providing enterprises with material resources.

\section{References}

Bauersoks Donald Dzh. (2006) Logistics: the integrated chain of deliveries. / Bauersoks Donald Dzh. Kloss David, 640 p.p

Mohamed Syazwan Ab Talib, Abu Bakar Abdul Hamid (2014) Application of Critical Success Factors in Supply Chain Management //nt. J Sup. Chain. Mgt Vol. 3, No. 1, pp. 21-29

Paula Santos Ceryno, Luiz Felipe Scavarda, Katja Klingebiel, Gökhan Yüzgülec (2013) Supply Chain Risk Management: A Content Analysis Approach // International Journal of Industrial Engineering and Management (IJIEM), Vol. 4 No 3, pp. 141-150

Klavdij Logožar (2013) The specifics of supply chain integration with small and medium-sized enterprises //Naše gospodarstvo / Our Economy Vol. 59, No. 1-2, pp. 3-12

Gunasekaran A., Ngai E.W.T. (2003) The successful management of a small logistics company // International Journal of Physical. Distribution \& Logistics Management Vol. 33 No. 9, pp. 825-84

Kot S., Grondys K., Szopa R. (2011) Theory of inventory management based on demand forecasting // Polish journal of management studies. vol.3, pp. 148-156

Panko A. (2010) Management of chains of deliveries to Microsoft Dynamics ${ }^{\circ}$ NAV. - M.: WHAT Pablisherz, 202 pp.

Demchenko A.I. (2014) Management of relationship with clients in logistic chains//Humanitarian scientific researches. - March No. 3

Butrin A.G (2011) Methodical bases of management of chains of expenses of the integrated enterprises. Chelyabinsk: Publishing center UGU, 2011. - pp. 105. 